
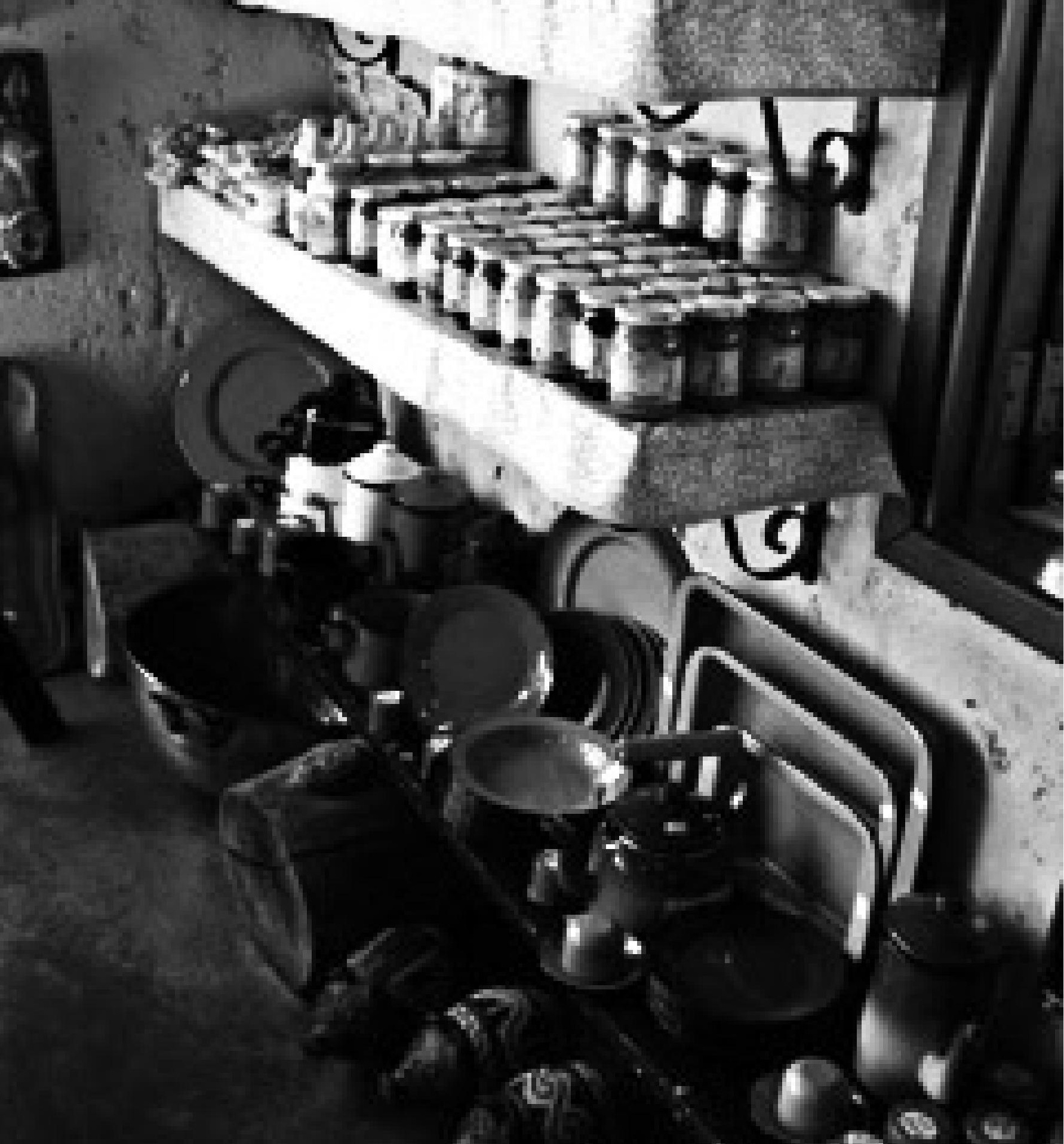


\section{A identidade territorial enogastronômica como elemento de sustentação turística regional: A experiência do Tirol e Südtirol}

Territorial enogastronony identity as a point of regional touristic development: Tyrol and Soul Tyrol Experience

Roberto do Nascimento e Silva ${ }^{1}$

1 Doutor em Desenvolvimento Regional pela Universidade de Santa Cruz do Sul (UNISC). Docente na Universidade de Santa Cruz do Sul (UNISC), Santa Cruz do Sul, Rio Grande do Sul, Brasil. E-mail: rsilva@unisc.br 


\section{RESUMO}

No que diz respeito ao turismo, percebe-se que, espaços antes isolados, ou então com relações restritas em escala regional, tornam-se partes de um sistema de abrangência global que acaba por sofrer influências da padronização de produtos e da redefinição de territórios. Todavia a enogastronomia busca oportunizar a reação regional através do oferecimento de produtos particulares, impregnados de cultura, em que sociedades reconhecem suas identidades e atraem visitantes para a localidade, fazendo com que estas sejam destaque em experiências de promoção e desenvolvimento do turismo regional. Neste sentido, o artigo tem por objetivo analisar a identidade territorial enogastronômica como alicerce do turismo regional no território tirolês e, utilizando para isso, o materialismo histórico dialético como marco teórico metodológico. Se entende por enogastronomia, a união de segmentos de alimentos e bebidas sustentada por um tripé que compreende o produtor rural, as empresas (vinícolas e restaurantes) e o território.

Palavras-chave: Cultura. Enogastronomia. Identidade territorial. Turismo. Tirol e SüdTirol.

\section{ABSTRACT}

With regard to tourism, it is clear that areas previously isolated, or with restricted relations on a regional scale, become parts of an overall comprehensive system that turns out to be influenced standardization of products and the redefinition of territories. However the enogastronomy create opportunities for regional reaction by offering particular products, impregnated with culture, where societies recognize their identities and attracting visitors to the region, standing out in the promotion of experiences and development of the regional tourism. The article aims to analyze the Territorial enogastronony identity as a point of regional touristic development in Tyrolean territory and, making use of the dialectical historical materialism as a methodological theoretical framework. It is understood by enogastronomy, the union bewteen food and wine company sustained for a tripod comprising the farmers, companies (wineries and restaurants) and the territory.

Keywords: Enogastronomiy. Territorial identity. Tourism. Tyrol and South Tyrol.

\section{INTRODUÇÃO}

O território abriga possibilidades e simultaneidades, trata-se de um organismo em transformação, onde não há somente um ponto de partida puro e original. Relações de poder, delimitações geográficas, funções administrativas e elementos simbólicos coexistem espacialmente e partem do pressuposto de que os territórios são produzidos por meio da ação de sujeitos na produção de valores mais ou menos hierárquicos no espaço. 
Nesse sentido, a noção de território privilegia diversas abordagens, dentre os quais, se destacam as definições de Raffestin (1993), quando destaca o poder exercido por pessoas ou grupos como base para a definição de território. Em outras palavras, poder e território devem ser relacionados conjuntamente para que o conceito se consolide.

As relações de poder são multidimensionais e exercidas em todas as escalas, dentro e fora do território. "O poder é a chave e em toda a relação circula o poder que não é nem possuído nem adquirido, mas simplesmente exercido" (RAFFESTIN, 1993, p.7).

Para Flores (2007) o conceito de território incorpora um jogo de poder entre os atores que atuam num espaço. Como resultado desse jogo de poder, se define uma identidade relacionada a limites geográficos, ou ao espaço determinado. $O$ território surge, portanto, como resultado de uma ação social que, de forma concreta e abstrata, se apropria de um espaço (tanto física como simbolicamente), e por isso é um processo de construção social (FLORES, 2007, p. 4).

Neste contexto, percebe-se que o território e suas dinâmicas territoriais emergem territórios turísticos que associados a outros atributos da materialização do espaço como a enologia e a alimentação, proporcionam o desenvolvimento do fenômeno turístico em nível regional.

Assim, verifica-se que estes espaços se tornam campos privilegiados para estudos, como o caso do território do Tirol na Áustria e do SüdTirol na Itália. Apesar de serem territórios geográfica, administrativa, política e economicamente separados, seus aspectos territoriais e culturais os aproximam, configurando-os como uma única região, alicerçada na identidade do povo, na sua história nos seus hábitos e costumes, na sua enogastronomia e no seu estilo de vida.

O Tirol e o SüdTirol podem ser considerados objeto de estudos, pois, estes passaram por diversas transformações no curso do último século a partir de características culturais (idioma, folclore, costumes, turismo e gastronomia), políticas (guerras e jogos de poder), geográficas (perdas de fronteira) e administrativas que foram se modificando através dos tempos.

Diversos autores analisaram as transformações neste território a partir de distintas visões, todavia, sob o contexto da enogastronomia, este território apresenta lacunas de interpretação.

Neste sentido, o artigo tem por objetivo analisar a identidade territorial enogastronômica como alicerce ao desenvolvimento do turismo regional no território tirolês. A metodologia aplicada neste estudo, se sustenta no materialismo histórico dialético, pois esta, interpreta a realidade através de um caminho epistemológico 
dinâmico, provisório e em constante transformação. Buscou-se também conhecer in loco o caso tirolês, o que possibilitou gerar um conhecimento mais contextualizado, voltado para a interpretação e baseado em populações de referência, determinadas pelo pesquisador (André 2005).

Como populações ou universo da pesquisa, optou-se por visitantes da região tirolesa, produtores rurais que fornecem matéria prima para o setor enogastronômico e proprietários das empresas ligadas ao setor. Não se definiu um número de entrevistados, mas a repetição das respostas destes, a partir da aplicação de um questionário qualitativo relacionando as perguntas ao tema geral.

Os dados levantados nesta pesquisa serviram para conhecer o arranjo regional atual, além de compreender como a identidade enogastronômica tirolesa contribui para o desenvolvimento do fenômeno turístico no território em questão.

Na sequência deste artigo, apresenta-se a uma síntese das relações entre o território, o turismo e o saber fazer enogastronômico, bem como o caso tirolês e que culminam a posteriori numa análise reflexiva acerca da identidade territorial enogastronômica como elemento de sustentação turística do território regional

\section{O TURISMO E A IDENTIDADE TERRITORIAL ENOGASTRONÔMICA}

No que diz respeito ao turismo e a identidade enogastronômica de um território, percebe-se atualmente que, espaços antes isolados, ou então com relações restritas em escala regional e/ou nacional, tornam-se partes de um sistema de abrangência global.

Apesar deste sistema atingir, praticamente toda a economia mundial, há uma série de ações e reações existentes na dinâmica entre o global e o regional nos territórios que acaba por particularizar os territórios.

O setor enogastronômico, como um promotor da valorização dos espaços regionais, da tradição e da prática produtiva regional, acaba também por sofrer influências externas, pois sofre com a disseminação de empresas globais dentro de seus territórios.

A enogastronomia tem papel de destaque em algumas experiências de desenvolvimento do turismo regional. Através dela, as regiões e as sociedades criam suas identidades, fortalecem seus hábitos e costumes, resgatam suas crenças, preservam seu folclore, além de transmitirem tais valores para as futuras gerações. Isto significa estar impregnada de cultura, identidade, expressões, marcas e de um modo particular de agir. 
É possível identificar costumes e tradições que não se revelam de forma palpável, ligados ao imaginário de cada pessoa, no despertar dos sentidos (visão, audição, paladar, tato e olfato), no expressar das diferenças, das semelhanças, das crenças e do sentimento de pertencimento.

Neste sentido, apresenta-se a enogastronomia como a união de segmentos de alimentos e bebidas sustentada por um tripé que compreende o produtor rural, as empresas (vinícolas e restaurantes) e o território, onde são desenvolvidos e aplicados conhecimentos teóricos, técnicos e práticos no oferecimento de produtos particulares e de qualidade aos consumidores finais (SILVA, 2015, p. 14).

Pecqueur (2009) cita a qualificação do produto como estratégia de mercado, pois o valor agregado ao produto regional o torna único e exclusivo. Neste caso, sua valorização se dá pela diferenciação (na forma de produção e vinculação territorial), independentemente de preço ou custo de produção, diferenciando-o assim dos demais produtos oferecidos pelo processo global.

Conceber o território como um espaço que possui forte relação com a história e as particularidades produtivas advindas deste, também é uma necessidade.

Assim como outros setores da economia, o turismo e a alimentação também são influenciados pela relação dialética entre a dimensão global e a dimensão regional, não apenas da valorização e formação de uma identidade territorial, mas também no desenvolvimento dos indivíduos atuantes no contexto regional.

Todavia, para compreender a enogastronomia como elemento de sustentação turística regional, faz-se necessário discutir o entendimento sobre terroir, pois deste partem todos os pressupostos que irão a correlacionar com a identidade territorial.

Para Tonietto (2007), o termo terroir veio a ganhar conotação positiva nos últimos 60 anos, quando a valorização da delimitação dos vinhedos nas denominações de origem de vinhos na França veio a balizar critérios associados à qualidade de um vinho, incluindo o solo e a variedade, dentre outros.

A palavra terroir passou a exprimir a interação entre o meio natural e os fatores humanos. E esse é um dos aspectos essenciais do conceito, de não abranger somente aspectos do meio natural (clima, solo, relevo), mas também, de forma simultânea, os fatores humanos da produção, de escolha de variedades, aspectos agronômicos e aspectos de elaboração dos produtos. (TONNIETO, 2007, P.3)

Para Valduga e Valduga (2007), este processo de produção regional está relacionado às características geográficas concretas (condições de clima, solo); as características das matérias primas agrícolas (as vinhas, o leite, o café, a carne); as técnicas 
de produção específicas na produção de produtos regionais, (o vinho, o queijo, os embutidos, o café), e ao modo de vida e aos costumes da sociedade que, em última análise, dá vida ao terroir.

O termo é dotado de uma capacidade de gerar produtos particulares que Ihe conferem originalidade e características próprias, seja através de características físicas e biológicas ou de características históricas e socioeconômicas que conferem um produto acabado percebido como autêntico e identificável pela sua tipicidade.

No caso da enogastronomia, verifica-se a contribuição para o desenvolvimento do território turístico, pois, recupera e valoriza tradições territoriais, certifica e divulga os produtos e serviços regionais, valoriza os produtores rurais, identifica a produção através de selos regionais, destaca o processo histórico social, expõe as particularidades do território e apresenta um modo de vida regional, diferenciado e original, que torna-se reconhecido por sociedades e mercados que atuam em escalas globais, além de atrair visitantes para a localidade.

Com relação às identidades territoriais, no caso dos territórios, pode-se salientar que estas são constituídas a partir de fronteiras que os grupos determinam, através de fronteiras sociais simbólicas que adquirem limites territoriais, com base nas relações histórico-culturais destes grupos sociais.

A identidade territorial se constrói no tempo, nutrindo-se de elementos sócio culturais, políticos e históricos necessários para alicerçar e fortalecer um sentimento de pertencimento capaz marcar, identificar e diferenciar a sociedade regional dos demais territórios, dados ou construídos.

Albagli (2004) salienta que o sentimento de pertencimento é um modo de agir no âmbito de um dado espaço geográfico, que significa a caracterização de uma noção de territorialidade, onde as relações sociais e a localidade estão interligadas, fortalecendo assim o sentido de identidade, e refletindo num sentimento de pertencimento.

Entretanto, para fortalecer os territórios, através de laços identitários, é necessário valorizar aquilo que um dado território tem de seu, suas particularidades, enquanto patrimônio sócio cultural, econômico e ambiental.

Portanto, desta forma, pode-se afirmar que a identidade territorial é o resultado do processo de produção de cada território, construída por múltiplas relações (sócio culturais, políticas, econômicas e ambientais) que se renovam todos os dias nos territórios, configurando o que se conhece por região. 


\section{O TERRITÓRIO TIROLÊS: UM ESTUDO DE CASO}

Para analisar a identidade territorial enogastronômica como elemento de sustentação turística no território tirolês, além de interpretar os dados resultantes da pesquisa, foi necessário realizar um estágio in loco na região tirolesa entre os meses de julho de 2013 e março de 2014.

Região esta que está localizada a oeste do território austríaco e ao norte do território italiano, fazendo fronteira, ao norte com o território da Baviera, na Alemanha, ao sul com os territórios da Lombardia e Trentino, na Itália, a oeste com o território de Voralberg, na Áustria e com os Alpes na Suíça e, a leste, com o território de Salzburgo e Kärnten, na Áustria. (GEOGRAPHIE ATLAS, 2013), conforme apresenta a figura 1.

Figura 1 - Delimitação da área do Tirol

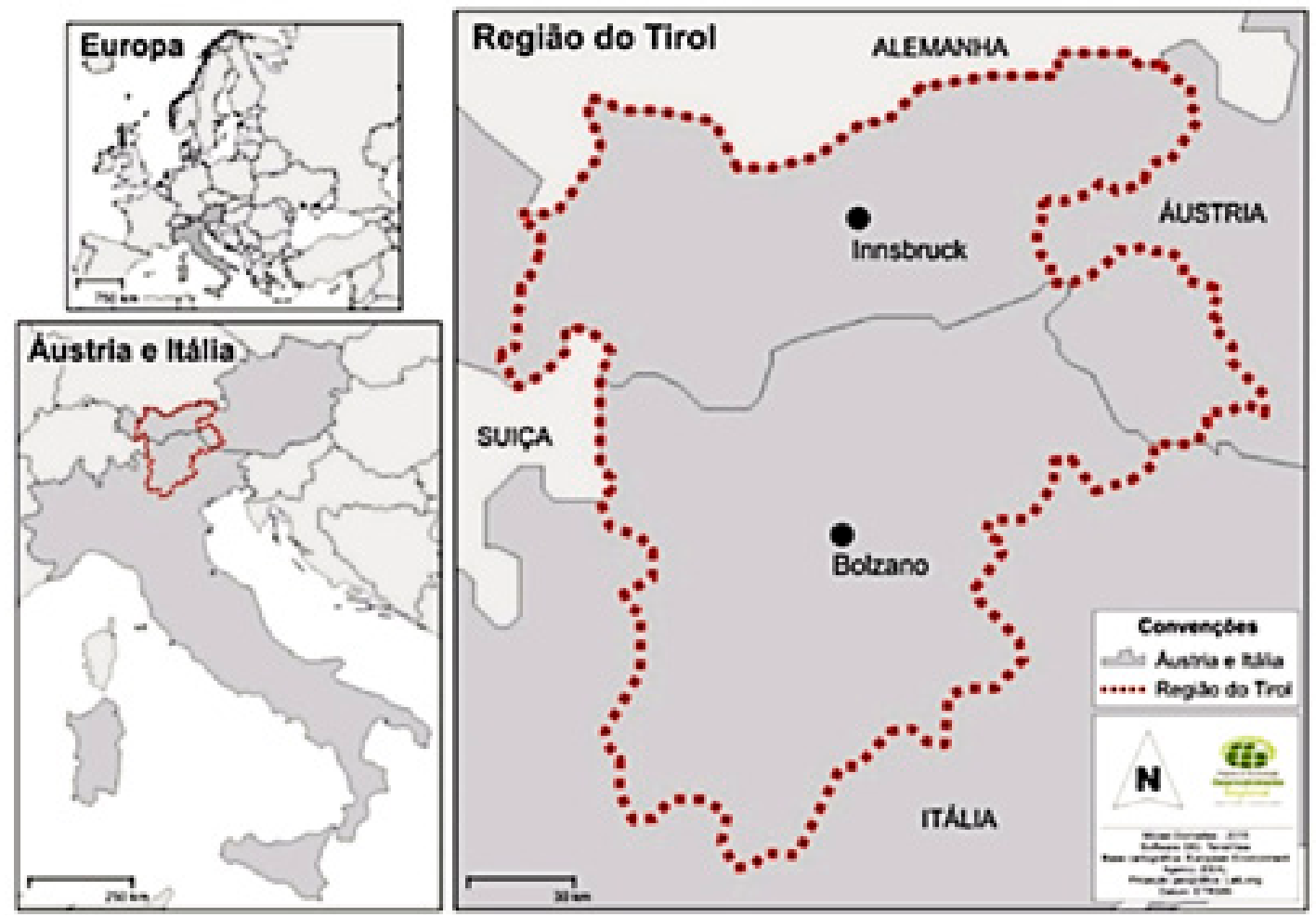

Fonte: Base cartográfica European Environment Agency, adaptado por Dornelles, 2015

Na região encontram-se empreendimentos enogastronômicos, rotas vitivinícolas, como à estrada del vino e às vinícolas na região de Bolzano (Itália), à Käse Strasse e às queijarias das proximidades da região de Innsbruck (Áustria), pequenos produto- 
res de speck (tipo de presunto) e schnapz (tipo de aguardente de frutas ou flores), de produtos enoalimentares regionais nos supermercados e casas especializadas, além de festivais gastronômicos e feiras rurais.

Essas atividades viabilizaram o aprofundamento sobre a produção agropecuária do território tirolês e o modo de vida de seus produtores, principalmente nas zonas periféricas aos polos de Innsbruck e Bolzano, o que contribuiu para uma melhor análise e compreensão das particularidades regionais no processo de formação da identidade enogastronômica destes territórios.

De acordo com o Statistik Austria (2010) e o Istituto Provinciale di Statistica (2010), a região do Tirol (Austríaco e Italiano) possui uma área total de $20.047,71 \mathrm{~km}^{2}$, com uma população de 1.207.239 habitantes. O PIB per capita anual da região é de aproximadamente $€ 29.824,00$ e sua economia é composta pela produção agropecuária $(6,6 \%)$, por indústrias $(24,1 \%)$ e pelo setor de serviços $(69,3 \%)$.

Na produção agropecuária, a região é fortemente identificada com a produção de leite, queijos e seus derivados, representando quase $50 \%$ da produção agrícola total (TIROL UNSER LAND, 2013). O segmento leiteiro do Tirol é valorizado e reconhecido através dos derivados (queijos de montanha) com indicação geográfica reconhecidos pela União Europeia, produtos lácteos com selos de certificação regional, produtos orgânicos, além de uma rota do queijo (Käsestrasse), que proporciona aos visitantes o contato com os costumes dos produtores rurais, o manejo das vacas e os processos de fabricação dos queijos, degustações e compras no atacado e varejo destes produtos nas próprias indústrias (queijarias) ou em casas especializadas da região.

Conforme Daugstad e Kirchengast (2013) a rota dos queijos e as certificações proporcionam a toda a cadeia produtiva do leite tirolês, vantagens competitivas em prol da região que fortalecem suas particularidades e consequentemente valorizam seus produtos.

Além de produtos derivados do leite, a produção agropecuária tirolesa se destaca também pela produção de charcuteria (speck, embutidos, linguiças, salsichas), sch$n a p z$, uvas, vinhos e derivados, maçã e pera, além da grande produção de hortifrutigranjeiros orgânicos (linhaça, centeio, trigo, girassol, mel, geleias, compotas, sucos, frutas, verduras, entre outros). A União Europeia (2013) destaca que a Áustria é o país com maior produção de orgânicos no mundo, cerca de $19,7 \%$ de suas áreas cultivas são orgânicas.

O turismo no Tirol está fortemente ligado à gastronomia regional e a prática de esportes de inverno (montanha), o que movimenta uma série de empresas pres- 
tadoras de serviços, como meios de hospedagem, escolas de esqui, lojas de artesanato, bares, restaurantes, guias de turismo, locadoras de veículos, comércio de equipamentos esportivos, entre outros.

O que chama a atenção no turismo tirolês são as fazendas próximas a Bolzano, voltadas ao agroturismo. Estas fazendas desenvolvem atividades complementares às cotidianamente realizadas na propriedade, sendo executadas pela própria família e estão associadas às práticas familiares agrícolas, mas que também agregam serviços turísticos à produção agropecuária, e que, ao mesmo tempo despertam a atenção e encantam os visitantes destes empreendimentos.

De acordo com a Associação Italiana de Agroturismo (2013), na região o turismo é compreendido como "o lazer ao ar livre rodeado pela natureza em um ambiente rural, é rico em cultura, tradições autênticas e produtos agrícolas de alta qualidade".

Estas propriedades proporcionam aos visitantes a experiência de vivenciar a vida típica e cotidiana de uma família rural tirolesa, conhecer sua cultura, seus costumes, pois os turistas têm a oportunidade de: a) observar in loco e saborear a gastronomia local através de degustações enogastronômicas oferecidas nos menus com produtos agrícolas produzidos nas propriedades (queijos, uvas e vinhos, salames e salsichas, pães, mel, azeitonas, geleias, sucos naturais, pratos à base de carne de porco, ovelha, coelho e vaca); b) de conhecer a história da região através de contos e conversas com os proprietários do local; c) de praticar esportes, como a pesca esportiva, a equitação, as caminhadas e os esportes de montanha (esqui, snowboard, escaladas), além usufruir do contato direto com o meio rural.

Ainda de acordo com o Tirol Unser Land, (2013) ao mesmo tempo em que se busca a geração de renda e o sustento familiar com a comercialização dos produtos regionais, há uma grande preocupação com a "marca regional" no oferecimento destes produtos ao mercado, isto é, os produtores têm consciência de que o produto tirolês deve ser reconhecido e diferenciado dos demais produtos oferecidos no comércio, seja pelo reconhecimento dos consumidores (história, cultura e traços de identidade do território no produto), pelas suas características organolépticas (cor e aroma, sabor, textura) ou por suas características de produção (método, know how dos produtores, certificações da União Europeia ou certificações regionais).

O "saber fazer" local dos produtores tiroleses e sua interação com o meio natural é notoriamente reconhecido pela sociedade regional, não apenas como fonte de geração de alimentos, mas também como paisagem cultural e identitária da região.

Neste sentido, é válido salientar que os proprietários rurais tiroleses criaram uma 
paisagem cultural única, que atrai um grande número de turistas que vêm ao Tirol para conhecer estas formas de produção agropecuárias e se reconhecer através dos produtos e pratos oferecidos em restaurantes típicos e casas especializadas em gastronomia nas cidades tirolesas.

Com relação à gastronomia tirolesa, a mesma deriva do império Austro-Húngaro e recebe forte influência da cozinha Alemã (Baviera), da cozinha Tcheca, da cozinha Italiana e da cozinha Húngara, cozinhas estas que se destacam por trabalharem com os alimentos assados e cozidos como se apresenta no quadro a seguir.

Conforme Duràn (2011), traços marcantes que identificam a cozinha regional tirolesa estão apresentados nos pratos à base de carne suína, (speck, Wiener Schnitzel), gado bovino (Gekochtes, Rindfleisch e Gulasch), massa (Käsespätzle, spatzl e gröstl) e batatas. Isto é, uma cozinha calórica, rica em proteína animal, gordura e carboidratos, podendo popularmente ser reconhecida também como uma cozinha "pesada".

Para o autor, essas características estão relacionadas a duas condições básicas: às condições geográficas (clima, temperatura e relevo) da região e à herança deixada pelo Império Áustro Húngaro e pelos povos que habitavam o Tirol durante o período de guerras, bem como de suas reorganizações territoriais.

O autor destaca ainda que estes aspectos contribuíram para o fortalecimento da identidade da cozinha tirolesa, pois nestas trocas territoriais foram se mesclando os sentimentos de pertencimento, junto a ingredientes e formas de preparo, com diferentes sabores e aromas, auxiliando desta maneira, na formação da identidade territorial enogastronômica do Tirol.

A cozinha tirolesa não possui grande diversidade de pratos e ingredientes, como a gastronomia italiana e brasileira, por exemplo, mas ela conserva traços culturais, modos de preparo tradicionais e serviços de mesa originais que "andam" meio que na contramão dos processos de padronização dos serviços de restauração mundo a fora. E, é justamente esse processo contrário, esse passado contra o presente, esse clássico contra moderno e esse "velho" contra o novo que a fortalece e a torna tão encantadora e atrativa aos visitantes.

Um exemplo deste particular é encontrado nos restaurantes típicos tiroleses que possuem um estilo arquitetônico que resgata a vida e o modo de ser dos moradores da região, facilmente identificados através dos detalhes e dos objetos de decoração nas paredes, na apresentação dos pratos, das vestimentas dos garçons e no modo de atender aos clientes.

Outro exemplo deste particular são os Würstwagen (espécie de food truck) espe- 
cializados em lanches típicos regionais à base de diferentes tipos de linguiças e salsichas como o St. Johaner, o Frankfurter, o Currywurst, o Burenwurst, o Käsekrainer, o Bosna (tipo de cachorro quente com salsicha Bratwurst, cebola, e uma mistura de mostarda, ketchup e curry), e os Kaminwurzen e o Fleischkäse-Semmel (pães de carne de porco, acompanhados de mostarda, chucrute e pão).

Mesmo que de forma tímida e incipiente, esta parte do segmento gastronômico tirolês assume também o papel de identificação do território e valorização da cozinha típica, pois oferece a possibilidade de se conservar os hábitos alimentares em todos os tipos de refeições oferecidas.

A gastronomia tirolesa se destaca ainda pelo oferecimento de sobremesas como o: a) Apfelstrudel (torta de massa folhada recheada com maçãs e canela, servida quente ou fria); b) o Palatschinken (crepe guarnecido de calda de nutella com açúcar de confeiteiro); e c) a Sachertorte (espécie de torta com massa de pão de ló, recheada com damascos e coberta com creme duro de chocolate) e pela grande produção de pães orgânicos, facilmente encontrados em Backereis (padarias da região), regionalmente certificadas.

Com relação à região sul do território tirolês (SüdTirol), pode-se afirmar que o mesmo está cercado por montanhas de grandes altitudes, como os dolomites (montanhas de rochas ricas em carbonato de cálcio e magnésio, de coloração acinzentada), o que dificulta a produção agrícola. Conforme o Istituto Provinciale di Statistica (2006) somente quinze por cento (15\%) desta parte do território tirolês possui áreas agricultáveis.

De acordo com o Tirol Atlas (2000), a produção agrícola na região está voltada às seguintes atividades: a) pastagens para o gado e produção leiteira com 18.908 ha, o que representa $57,1 \%$ de toda área cultivada na região; b) a produção de fruticultura com 8.823 ha, o que representa $26,6 \%$; c) a produção vitícola com de 4.810 ha, o que representa $14,5 \%$ da área e d) outros plantios com (1,8\%).

A Associação de Vinhos do SüdTirol (2013) salienta que apesar da vitivinicultura sul tirolesa produzir somente um por cento (1\%) da produção vitícola italiana, $98 \%$ destes vinhos produzidos possuem certificação de indicação geográfica - Denominação de Origem Controlada - reconhecidos pelo sistema internacional de certificação de produtos agrícolas e vinhos da União Europeia.

Os vinhedos do SüdTirol são considerados de montanha, pois, suas vinhas se encontram em locais que variam de trezentos (300) metros a mil (1.000) metros de altitude (ASSOCIAÇÃO DE VINHOS DO ALTO ADIGE, 2013).

A Associação destaca também que a região possui sete zonas vitivinícolas, trinta e 
seis produtores rurais cadastrados, quarenta e oito vinícolas produtoras de vinhos branco, tinto e rose (finos e de sobremesa), dezessete vinícolas produtoras de espumantes e vinte e sete enólogos atuantes na região.

A produção vitícola tirolesa está localizada próxima ao polo de Bolzano e encontra-se em uma posição geográfica privilegiada para o cultivo de uvas de montanha, pois possui um solo vermelho e de rápida absorção de água) com proteção dos alpes tiroleses, com ventos quentes oriundos do mediterrâneo, umidade favorável, com intensidade de luz solar em média de trezentos dias no ano e grandes variações de temperatura propícias para o plantio de uvas que, aliadas aos fatores humanos de modo de preparo e de manuseio da terra influenciam favoravelmente à produção da vitivinicultura e proporcionam um terroir único, cheio de características e particularidades (ASSOCIAÇÃO DE VINHOS DO ALTO ADIGE, 2013).

Os vinhos do Tirol do Sul são o resultado da combinação perfeita de três fatores: a dedicação do viticultor, arte do enólogo e as condições climáticas e de solo.

$E$, a soma total destes fatores constitui a singularidade da área vitícola tirolesa e a torna reconhecida internacionalmente pela qualidade dos vinhos oferecidos elaborados a partir de uvas brancas como a Pinot bianco, Chardonnay, Pinot grigio, Gewürztraminer, Müller Thurgau, Sauvignon, Sylvaner, Moscatto Giallo, Riesling, Kerner, Veltliner, Riesling Itálico e uvas tintas como a Schiava, Lagrein, Pinot Nero, Merlot, Cabernet, Rosenmuskateller e Malvasier que produzem vinhos de coloração brilhante, com taninos suaves, aromas e sabores delicados, finos e equilibrados que lembram frutas, flores e ervas de montanha.

No território, encontra-se ainda uma rota de vinho denominada Strada del Vino, que proporciona aos visitantes inúmeras atividades relacionadas ao lazer, a cultura da uva e a enologia da região, verificadas através das observações de campo através da visita ao museu do vinho e conhecimento sobre a história da uva e dos produtores da região (sua chegada, plantios, ferramentas, primeiros agricultores, formas de condução das videiras e sua evolução, primeiros vinhos, entre outros) e das visitas guiadas, denominadas wine safaris, onde se teve a possibilidade de visitar as vinícolas da região e realizar degustações dos vinhos produzidos ao longo da rota, bem como obter informações sobre a cultura local e de seus produtores.

É interessante destacar ainda, que a rota dos vinhos pode ser feita de bicicleta, incentivando desta forma a sustentabilidade local.

Outra particularidade da rota Strada del Vini, diz respeito a um serviço denominado Academia do Vinho, onde enólogos e sommeliers da região oferecem cursos 
sobre o estudo da uva para grupos de estudantes, apreciadores ou especialistas em vinho, realizados nas próprias vinícolas ou meios de hospedagem da região, harmonizados com a cozinha típica tirolesa.

É importante ressaltar ainda que outras particularidades regionais também estão impregnadas em diversos elementos que caracterizam a enogastronomia tirolesa, como: a) apresentações de grupos folclóricos nos restaurantes e em diversas atividades e eventos na região; b) nas especificações de pratos elaborados a partir de produtos regionais tiroleses nos cardápios dos restaurantes; c) na divulgação de produtos regionais tiroleses em casas especializadas e supermercados, bem como do destaque nas notas fiscais destes estabelecimentos relacionados aos produtos regionais; d) na valorização dos vinhos tiroleses em casas especializadas; e) nas feiras rurais diárias e semanais da região formadas exclusivamente por produtos regionais; f) na sinalização turística dos roteiros enogastronômicos nas rotas do queijo e dos vinhos; g) nos postos de informações turísticas e sites especializados; h) e principalmente no orgulho dos moradores, dos trabalhadores e de produtores da região em dizer que são tiroleses e ou sul tiroleses, independentemente da divisão territorial e geográfica existente, verificadas através de observações de campo.

O setor se utiliza ainda de campanhas de marketing organizadas em conjunto com o governo para reforçar a interação econômica da região e sensibilizar os consumidores para utilizar produtos regionais, pois estes são sinônimos de produtos superiores e de qualidade e que consequentemente imprimem qualidade aos pratos e produtos oferecidos nos estabelecimentos da região.

A participação do Estado nas ações em prol do desenvolvimento da enogastronomia tirolesa não se limitam somente a campanhas de marketing ou auxílio no fomento de associações, mas também: a) na criação de faculdades agrícolas, onde os alunos aprendem sobre todo o manejo e atividades agrícolas; b) no controle veterinário regional, para descartar problemas de saúde relacionados ao consumo de produtos de origem animal; c) no pagamento de salários e benefícios para os agricultores de montanha, como forma de compensação devido aos problemas estruturais e desvantagens deste tipo de produção; e d) no suporte para os agricultores que desenvolvem medidas favoráveis a gestão do ambiente e do território, afim de, garantir que as florestas sejam manejadas como um espaço de lazer e de proteção para as gerações futuras. (TIROL UNSER LAND, 2013).

Cabe destacar ainda outra importante particularidade do território tirolês. Ela diz respeito aos produtos com certificações de indicações geográficas reconhecidos pela União Europeia (UE) e aos produtos com certificações de qualidade regional 
que auferem destaque internacional relacionado à produção agropecuária.

A maçã gala, as uvas brancas e tintas, o speck, o schanapz, e os queijos de montanha são exemplos de produtos que fortalecem a identidade do território tirolês, pois estes representam um saber fazer local e um terroir único que confere aos produtores da região, a exclusividade da produção e desperta para o turismo regional.

Neste sentido, percebe-se o Tirol como uma região desenvolvida, que entende a enogastronomia como um elemento de sustentação turística da região, pois esta associa sua paisagem turística regional ao típico, ao original, ao autóctone e, por isso mesmo, imprime significado e desperta a curiosidade dos visitantes tiroleses.

\section{RESULTADOS DA PESQUISA}

A partir da coleta das informações realizadas através das entrevistas, percebeu-se a interferência da enogastronomia no processo de desenvolvimento do turismo na região tirolesa.

Verificou-se que, além do conhecimento sobre o processo histórico de formação do território, a enogastronomia proporciona um atrativo particular aos visitantes da região e impulsiona o turismo regional, seja através de seus produtos reconhecidos (indicações geográficas), de sua cozinha tradicional, de seus food trucks (würstwagen) especializados, de seus vinhos, de seu povo, ou de seus saber fazer que identificam e particularizam territorialmente a região.

Esta cultura proporciona a entrada de divisas, também gera emprego e renda para os trabalhadores, cria subprodutos enoturísticos e fortalece a imagem do território, pois este se torna exclusivo e particular frente a demais territórios mundo a fora.

Para Silva (2015), os próprios agricultores reconhecem que a atividade possibilita a descoberta de toda região e o "discurso turístico" é recorrente no destino, isto é, de algum modo, todos os entrevistados tiveram ou tem contato com a atividade turística.

Para o autor, esta dimensão social e cultural em incorporar processos enoalimentares que fomentem o desenvolvimento das sociedades, contribui também para a formação da identidade social, que levam consigo a expressão de seus estilos de vida. Através da enogastronomia, se expressam marcas do passado, da história, da sociedade e da região a qual se pertence.

Neste sentido, pode-se destacar que os hábitos da sociedade estão além das sensações relacionadas a cores e sabores dos alimentos, eles diferenciam valores sociais e culturais como a religião, a etnia e a história social. 
Desta forma, pode-se dizer que a maneira de preparar os alimentos e os ritos cotidianos estão territorialmente impregnados e enraizados no modo de ser regional, o que atrai visitantes e faz parte do patrimônio cultural da localidade.

Faz-se necessário compreender ainda que a enogastronomia é um importante atrativo turístico e cultural para o território, principalmente quando através dela pode-se entender o valor e a maneira como se desenvolve. $O$ que remete a ideia de traços e expressões culturais do Tirol, independentemente da situação geográfica ou política demarcada. Conhecer o território enoalimentar tirolês, é valorizar sua sociedade, seus hábitos e costumes e garantir a continuidade das tradições e da história para as futuras gerações.

Sob o ponto de vista do regional, se percebe também que a valorização da enogastronomia é necessária para a manutenção das tradições e das particularidades regionais.

Assim, o território torna-se atração de fluxos turísticos, pois, além da condição básica de se alimentar, a enoalimentação constitui um dos eixos do turismo cultural, o que viabiliza e universaliza as trocas humanas e o convívio entre as culturas, costumes e hábitos.

Percebe-se também que o uso da enogastronomia como ingrediente na exploração turística é interessante para os visitantes, pois, oferece o acesso ao patrimônio cultural e possibilita conhecer a história, a cultura e ao modo de viver da comunidade, isto é, quando esta perpassa por uma simbologia relacionada aos costumes sociais, é valorizada enquanto cultura e desperta nas pessoas a curiosidade em conhecê-la.

Dessa forma, verifica-se que a cultura alimentar tirolesa também é uma ferramenta mercadológica para os empresários da região, isto é, as cantinas e os restaurantes têm a consciência de que é necessário explorar a figura do típico (representada no vinho e na comida típica) para atrair os visitantes, afim de manter a viabilidade econômica da região.

Todavia, para Silva (2015) deve-se entender que a enogastronomia por si só não é capaz de se tornar um atrativo turístico cultural, ela deve sempre estar acompanhada de autenticidade da produção dos alimentos, pois desta forma, há a possibilidade de favorecer e valorizar a ideia de cultura imaterial, uma vez que para o turista não é apenas a degustação dos vinhos ou dos pratos típicos que o atrai para o destino, mas, também, a possibilidade de conhecer o modo de vida e o saber fazer local.

É necessário compreender que a enogastronomia tirolesa se torna uma importante ferramenta de desenvolvimento do turismo regional e de fortalecimento territorial, principalmente porque se caracteriza pelo sentimento de pertencimento ao território destacado. 
Nesta perspectiva, o autor destaca que se percebe um conjunto de elementos referenciados na tradição e articulados com o presente (através do processo histórico) para constituir algo particular e característico que é capaz de exacerbar o processo de identificação e diferenciação dos moradores do Tirol, fazendo com que estes se reconheçam e sejam reconhecidos diante de toda a diversidade cultural.

E esse é o fator determinante para sua autoafirmação e o reconhecimento tirolês, pois é o território que desperta o interesse turístico, favorece a estruturação e a organização produtiva local.

Desta forma, a identidade territorial tirolesa "cria uma corrente" que vai na contramão de processos globalizantes, pois nela, encontram-se elementos culturais que reafirmam o sentido de pertencimento por meio das relações simbólicas de representação, isto é, seus indivíduos.

Isto significa que o Tirol pode transformar seu patrimônio sócio cultural em âncora para o fortalecimento do processo de desenvolvimento do turismo regional.

Para Silva (2015), se verifica através das falas dos entrevistados, que a afirmação da identidade territorial é algo que não está planejado e sim, construído historicamente, através de traços culturais herdados, do imaginário dos moradores da região bem como de sua valorização.

Estes traços culturais criam uma atmosfera de identificação da sociedade tirolesa, que acaba por transcender aspectos relacionados à produção vitivinícola da região, assim como da atividade do enoturismo e do crescimento econômico.

Nesta direção, percebe-se no Tirol, assim como em outras regiões, o território se sustenta e apropria-se do sentido de lugar. Isso acontece porque as identidades para se realizarem precisam encontrar um referencial concreto, uma base de sustentação com características espaciais, geográfica e ou culturais.

Vale salientar ainda que o processo cultural que demarca a identidade territorial enogastronômica, pode ser construído por quaisquer grupos que persistam na afirmação ou na valorização de seu "lugar" como atributo de sua legitimação ou de sua diferenciação. Como é o caso do território tirolês.

Por fim, após essa reflexão pode-se verificar que as questões relacionadas à identidade territorial no Tirol, incorporam uma representação territorial de legitimação e diferenciação social que caracteriza o território para além da vitivinicultura, do enoturismo e da cozinha típica e que possibilita na região, a oportunidade de se degustar as tradições locais, a história da sociedade e os traços culturais deixados pelos imigrantes. 
Portanto, neste sentido, percebe-se que a enogastronomia também contribui para a formação de identidade territorial no próprio território tirolês, além de compreendê-la como promotora do turismo regional, tendo em vista que seus vinhos, sua gastronomia típica, seu território, seus atores sociais e o modelo produtivo da região, são objetos de interesse a serem conhecidos, estudados e observados por pesquisadores, estudantes, visitantes que têm interesses pela região. $\mathrm{E}$, que desta forma, torna-se base para a reação regional, frente aos processos hegemônicos e globalizantes na atualidade.

\section{REFERÊNCIAS}

ALBAGLI, S. Território e territorialidade. In: LAGES, V., BRAGA, C., MORELLI, G. (orgs). Territórios em movimento: cultura e identidade como estratégia de inserção Competitiva. Brasília: Sebrae, 2004.

ANDRÉ, Marli Eliza Dalmazo Afonso de. Estudo de Caso em Pesquisa e avaliação educacional. Brasília: Liber Livro Editora, 2005.

ASSOCIAÇÃO DE AGROTURISMO ALTO ADIGE. Bolzano. Disponível em: <http:// www.agriturismo.it/de/bauernhof/trentino-sudtirol>. Acesso em: set. 2013.

ASSOCIAÇÃO DE VINHOS DO ALTO ADIGE. Alto Adige Terra di Vini. Disponível em: <http://www.altoadigewinesusa.com/>. Acesso em: jan. 2014.

ASSOCIAÇÃO KÄSESTRASSE. Disponível em: <www.kaesestrasse.at>. Acesso em: out. 2013.

DAUGSTAD, Karoline. KIRCHENGAST, Christoph. Authenticity and the Pseudobackstage of Agritourism. Annals of Tourism Research, v. 43, pp. 170-191, Region Vorderland-Feldkirch and University of Innsbruck, 2013.

DURÁN, Xavier. I Sapori dell'Austria. Editorial Fisa Escudo de Oro: Escudo de Oro, 2011.

FLORES, Murilo. Da solidariedade social ao individualismo: Um estudo sobre o desenvolvimento do Vale dos Vinhedos na Serra Gaúcha. Santa Catarina: Tese de Doutorado/UFSC, 2007.

GEOGRAPHIE ATLAS. Altas de Geografia do Instituto de Geografia da Innsbruck Universität. Innsbruck, 2013.

ISTITUTO PROVINCIALE DI STATISTICA. Provincia Autonoma di Bolzano Alto Adige. Disponível em: <http://www.provinz.bz.it/astat/it/default.asp>. Acesso em: out. 2013.

KÄSESTRASSE. Cheese Route. Disponível em: http://www.kaesestrasse.at/. Acesso em: ago. 2013. 
KÖFLER, Werner. Zeittafel zur Geschichte Tirols. Disponível em: <http://www.tirol. gv.at/fileadmin/www.tirol.gv.at/themen/kultur/landesarchiv/downloads/zeittafel. PDF>. Acesso em: out. 2013.

PECQUEUR, Bernard. A guinada territorial da economia global. Política \& Sociedade - Revista de Sociologia Política, PPSP UFSC, 2009.

RAFFESTIN, Claude. Por uma geografia do poder. São Paulo: Ática, 1993.

SILVA, R. do N. A enogastronomia no processo de formação de identidade territorial do Vale dos Vinhedos/RS. Tese de Doutorado, Universidade de Santa Cruz do Sul, Santa Cruz, RS, Brasil, 2015.

STATISTIK AUSTRIA. Centro de Estatísticas da Áustria. Disponível em: <www.statistik. at/web_en/statistics/population/index.html>. Acesso em: set. 2013.

THE ATALS AUS TIROL. Disponível em: <http://www.svgopen.org/2002/papers/foerster_winter_atlas_of_tyrol/>. Acesso em: nov. 2013.

TIROL UNSER LAND. Tirol Nosso País. Disponível em: <www.tirol.gv.at/statistik-budget/>. Acesso em: set. 2013.

TONIETTO, Jorge. Afinal, o que é Terroir? Bon Vivant, v. 8, n. 98. Flores da Cunha, 2007.

UNIÃO EUROPEIA. Regulamento (CEE) no 2081/92 do Conselho, de 14 de Julho de 1992. Relativo à Protecção das Indicações Geográficas e Denominações de Origem dos Produtos Agrícolas e dos Gêneros Alimentícios. Certificações Geográficas. Disponível em: <http://ec.europa.eu/agriculture/quality/door/list.html>. Acesso em: ago. 2013.

VALDUGA, Gustavo. VALDUGA, Vander. Região, Vinho E Identidade: Uma Visão Sobre o Vale dos Vinhedos. Artigo. Bento Gonçalves, 2007. 